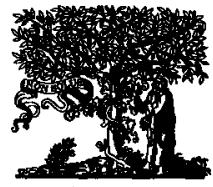

ELSEVIER
International Journal of Pediatric Otorhinolaryngology 32 (Suppl.) (1995) \$97-S99

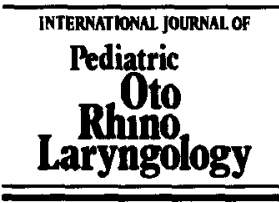

\title{
The management of difficult extubation in pre-term infants
}

\author{
L.J. Hoeve ${ }^{\mathrm{a}}$, C.D.A. Verwoerd ${ }^{\mathrm{b}}$ \\ ${ }^{a}$ Sophia Children's Hospital, Dr. Molewaterplein 60, Rotterdam, The Netherlands \\ ${ }^{b}$ Department of Otorhinolaryngology, Erasmus University, Rotterdam, The Netherlands
}

\section{Introduction}

Intubation and artificial ventilation have tremendously improved the survival rates of preterm infants, and both have become very common in Neonatal Intensive Care Units. When the infant is able to breathe without support, extubation is attempted. In most cases this succeeds and the otolaryngologist is not involved. However, in certain cases the extubation is followed by symptoms of severe respiratory tract obstruction, such as inspiratory stridor, dyspnea, and cardiac arrhythmia. Reintubation is unavoidable, and the otolaryngologist is consulted. The cause of the problem is unknown, but reintubation may be initiated by the pediatrician before the otolaryngologist arrives. Laryngoscopy is performed, in most cases revealing laryngeal damage as a complication of the intubation. Other causes are congenital anomalies, vocal cord paralysis, cysts tumors, etc., but this discussion will be limited to post-intubation damage. There remain important questions concerning the management of these patients. This study addresses: (1) the value of reintubation; (2) the need to differentiate treatment according to the injury; and (3) the duration of intubation until extubation is attempted again.

\section{Method}

The otolaryngology department was consulted for 23 NICU patients with failure to extubate ( 15 males and 8 females). Their mean post-conceptual age at birth was 30 weeks, the patients were intubated for a mean 34 days, and artificially ventilated during most of that period. The indications for the ventilation were respiratory insufficiency, hyaline membrane syndrome, diafragmatic hernia, etc. In all patients the diagnosis of post-intubation laryngeal damage was confirmed by laryngoscopy. Three categories of laryngeal damage were distinguished, as listed in Table 1.

Twenty-two out of 23 patients were successfully treated by reintubation for a mean duration of 17 days (range $=1-66$ days). The one failure was a patient in 
Table 1

Categories of intubation injuries in 23 cases of failure to extubate

\begin{tabular}{llccc}
\hline $\begin{array}{l}\text { Group } \\
\text { ID }\end{array}$ & Type of injury & No. of cases & $\begin{array}{l}\text { Successfully } \\
\text { treated by } \\
\text { reintubation }\end{array}$ & $\begin{array}{l}\text { Average } \\
\text { duration of } \\
\text { intubation }\end{array}$ \\
\hline A & Edema or superficial mucosal damage & 9 & 9 & $8(2-30$ days $)$ \\
B & Ulceration including the cartilage & 3 & 3 & $13(5-23$ days $)$ \\
C & Granulations & 11 & 10 & 27 (1-66 days) \\
\hline
\end{tabular}

Group $\mathrm{C}$ who needed a tracheotomy for severe circular granulations and severely retarded healing.

\section{Follow-up}

Complications of therapeutic reintubation occurred in 10 of 23 patients: Respiratory tract infection in eight patients, accidental extubation in eight, granulations in two, aspiration in two, feeding problems in one, and tube obstruction in one (some patients experienced more than one complication).

The patients were followed for a mean period of 34 months (range $=4-68$ months). None of the patients in Group A or B had symptoms of respiratory tract obstruction at the end of the follow-up period. In Group C, five patients had no complaints; but five others had symptoms of laryngeal dysfunction. Four of these last five had audible breathing or bouts of pseudocroup that disappeared after a few months, and one patient presented with scar tissue in the posterior commissura of the larynx about 3 years after the intubation.

\section{Management}

Therapeutic reintubation is the treatment of choice for difficult extubation in preterm infants in our institution. The duration of this therapy depends on the type of laryngeal damage, the success of the treatment, and the acceptance of the tube by the infant. Many Group A patients needed only a few days of reintubation, therefore extubation may be attempted after 3 days. Only if extubation fails is laryngoscopy performed. The duration of reintubation in Group B patients depends on the accompanying edema, but it is usually 3-7 days before extubation is attempted, followed by laryngoscopy if extubation fails. Reintubation should be attempted for 10 days in Group $C$ patients. If extubation fails, laryngoscopy is performed. Additional periods of reintubation are sometimes necessary until extubation finally succeeds. Tracheotomy is performed if extubation fails after reintubation therapy.

\section{Alternatives}

Apart from reintubation, the other possible therapies are immediate tracheotomy or anterior cricoid split. Tracheotomy has a much higher mortality in premature 
infants than in full-term infants, and it is only indicated if reintubation fails. The anterior cricoid split is not necessary for Group A or Group B patients, as they can be cured with reintubation alone. However, anterior cricoid split was not very successful for Group $\mathrm{C}$ patients. The granulations increased, and the patients required tracheotomy.

\section{Conclusions}

Difficult extubation from edema, superficial lesions, and deep ulcerations, can be treated successfully with reintubation. Granulations are more difficult to treat, requiring reintubation for a longer period. The long-term results still are in most cases satisfactory, but the treatment is not always successful. 